\title{
Boundary violation and sexual exploitation in psychiatry and psychotherapy: a review
}

\author{
Sameer P. Sarkar
}

\begin{abstract}
In psychiatric and psychotherapeutic practice, 'boundaries' delineate the personal and the professional roles and the differences that should characterise the interpersonal encounters between the patient/ client and the professional. Boundaries are essential to keep both parties safe. The author outlines the various types of boundary violation that can arise in clinical practice, their consequences (both clinical and legal), how professionals can avoid them and how health care institutions might respond, should they occur. He concentrates on sexual boundary violations, because these have been the subject of most empirical study.
\end{abstract}

The term 'boundary' in professional practice refers to the distinction between professional and personal identity. It is a metaphorical term for the construction and limits of professional identity, indicating not only the difference between the personal and professional roles, but also the structural differences that characterise the interpersonal encounters between the layperson and the professional. Boundaries serve only one purpose - to keep those on either side safe. Setting and keeping boundaries helps professionals and patients be secure in their identities and roles.

Boundary violations therefore represent an attack on the security of the relationship between the patient and the doctor. By discussing what can take place, how it happens and who can be harmed (both clinically and legally), I hope to show readers how to identify problems at an early stage and what to do to avoid the 'slippery slope'. I concentrate on sexual boundary violations, not because other types of violation are not harmful, but because sexual violations have been the subject of most empirical study.

\section{The extent of the problem}

Obtaining accurate epidemiological data on this subject is extremely difficult. Only the most serious violations are likely to be reported, so that more minor, or less physical, forms of violation are subject to underreporting. It is also possible that sexual boundary violations, like other types of sexual misdemeanour, are underreported because of issues to do with shame and guilt; and it is also possible that false accusations are comparatively overreported.

Most of the available studies are North American and focus on sexual boundary violations. Self-report studies of health care professionals, which ask about any history of sexual involvement with patients, suggest a prevalence range of $1-10 \%$. Specifically in relation to psychiatrists, the range was $2-6 \%$ for both a North American (Gartrell et al, 1986) and an Australian (Quadrio, 1996) sample. Since self-report is likely to be subject to bias, it may be useful to look at other sources of information. The American Psychiatric Association expels an average of 10 psychiatrists a year for sexual misconduct with a patient. This number has remained fairly stable over the past 10 years (although, of course, many more cases of misconduct would have been dealt with in other ways, for example by fines or temporary licence suspension). North American estimates have been cited as 'supportive of similar Canadian experience' (College of Physicians and Surgeons of Ontario, 1991).

Although the General Medical Council (GMC) in the UK no longer publishes details of the types of case that come before its Professional Conduct Committee, in the past approximately six cases of sexual misconduct were heard by the GMC each year, and of these only three resulted in a finding

Sameer P. Sarkar is a consultant in forensic psychiatry at Broadmoor Hospital (Crowthorne, Berkshire RG45 7EG, UK. E-mail: Sameer.Sarkar@wlmht.nhs.uk) and an associate in the hospital's psychotherapy department. He has studied law at the University of Northumbria at Newcastle and at Harvard Law School and has written on the law and ethics in forensic psychiatry. He teaches ethics of forensic psychiatry to psychiatrists and mental health professionals at two London medical schools. The opinions expressed are those of the author and do not reflect the opinions of West London Mental Health Trust, of Broadmoor Hospital or of the Ethics and the Law sub-committees of the Royal College of Psychiatrists, of both of which the author is a member. 
against the doctor. A finding of serious professional misconduct against a doctor would usually result in suspension or removal from the register. There have been studies of British psychologists' selfreported prevalence of sexual boundary violations, which found data similar to that of US studies (Garrett \& Davis, 1998). A charitable organisation in the UK that deals with clients abused by professionals reported that in 1998-1999, it received 23 complaints against psychiatrists and 60 against psychotherapists (although only 5 of these were medically trained).

In the USA, half the money in professional malpractice cases is spent on settlements and awards for complaints of sexual intimacy (Pope, 1991; Garrett, 2002). Although psychiatrists are three times as likely as psychotherapists to be sued for this kind of malpractice (Perr, 1989), epidemiological studies tend to suggest that there is no difference in rates between the different types of professional engaged in psychotherapy (Borys \& Pope, 1989).

There are no data available specifically about boundary violations by British psychiatrists and psychotherapists. Given the findings of the studies mentioned above, it would seem unwise to consider sexual boundary violations as a phenomenon from which they are immune. It is regrettable that the GMC no longer publishes details of professional misconduct cases and that the Royal College of Psychiatrists does not make available anonymised records of professional misconduct of its members: such information could be used for training.

\section{Varieties and mechanisms of boundary violation}

The Canadian Medical Association's code of ethics states succinctly: 'A physician ... will scrupulously avoid using the physician-patient relationship to gratify his own emotional, financial and sexual needs' (Canadian Psychiatric Association, 2002).

Boundary violations occupy a spectrum of behaviours that range in terms of frequency and harmfulness. Some authors make a distinction between boundary violations (which cause harm) and boundary crossings (which do not) (Gutheil \& Gabbard, 1993). The problem with this distinction is that boundary crossings may be repeated and may develop into boundary-violating behaviours over time; also, it is not clear who will decide whether a behaviour might or has caused harm. For example, are the behaviours listed in Box 1 boundary violations, boundary crossings or normal aspects of a particular psychotherapy?

The College's own document about clinical relationships in psychiatry, the Council Report
Box 1 Potential non-sexual boundary violations

- Excessive self-disclosure

- Special fee arrangements (low or free)

- Extending time beyond what was initially agreed

- Allowing telephone calls between sessions

- Extra-therapeutic business relationships

- Socialising with the patient

- Calling each other by first name

- Treating the patient as a friend or confidant/e

- Touching or frequent hugs

Vulnerable Patients, Vulnerable Doctors (Royal College of Psychiatrists, 2002), emphasises that it is the meaning of a behaviour to the patient, and not the intentions of the doctor, that determines harm.

The psychological mechanisms that give rise to boundary violations are complex and inevitably affected by conscious and unconscious factors in both the doctor and the patient. The College's Council Report draws attention to the vulnerabilities in both the doctor and the patient; vulnerabilities that are likely to be exposed in clinical relationships which necessarily involve the creation of an intimate space, with one person highly dependent on the other. For both parties, this is likely to trigger conscious memories of carers and being cared for (or not) and unconscious associations, identifications and fantasies about the relationship between carers and those for whom they care.

I draw a key distinction between the who-ness of the doctor's personal identity and the what-ness of his (or her) professional identity. Transference and countertransference meet and match around this distinction in both positive and toxic ways. The whoness of the doctor influences his or her what-ness; and patients are naturally curious about the whoness. It is tempting to use the who-ness, ostensibly to make the clinical relationship more valuable for the patient; but it is the what-ness that is ultimately the therapeutic agent for the patient. The duty of physicians is to address the patient's unconscious or pre-conscious desires to know not just their professional, but also their personal identity. Their personal identity may aid the formation and maintenance of their professional identity, but it is for them and them alone to be aware of the distinction between the two identities and to preserve it, at least within the therapeutic frame.

I will now give two fictional accounts of boundary violations, to demonstrate the different types and possible psychodynamic mechanisms. Each scenario involves a male doctor and female patient, reflecting the fact that most reported cases involve 
male doctors. Obviously, this is not to say that female doctors do not engage in this sort of behaviour. Doctors most likely to be involved in serious boundary violations are male, older and highly trained/respected. It is also likely that they have repeated such behaviours over time.

\section{Scenario 1: A 'mild' boundary violation}

Since the death of her husband following a protracted illness, Mrs A has been in twice-weekly psychotherapy with Dr B. She cannot drive and finds it difficult to attend the sessions on time. Dr B readily agrees to extend the time period to compensate for her lateness. Lately, she has been making lengthy telephone calls between sessions to discuss her feelings of loneliness and abandonment. She also tells Dr B of the difficulties she is having with the lawyer regarding her husband's estate and has asked whether he knows of a good lawyer who would not be so 'greedy and difficult'. In one of the sessions Dr $B$ tells her that his church has a good network, which offered him support when his wife died. He encourages Mrs A to meet him at the church after a service.

Excessive self-disclosure may be seen as a minor matter, but it is also the beginning of the blurring of the boundary between the professional and personal identities. Unless the patient is very disturbed, they will be curious about the person to whom they are entrusting important parts of themselves. Invariably, this curiosity has very little to do with the doctor's real identity, but has deeper, unconscious motives. If the therapist becomes too interested in disclosing her who-ness, she will run the risk of undermining the what-ness. Knowing how not to indulge in selfdisclosure in the face of seemingly harmless probing is a complex and subtle professional skill, which requires constant attention (Yalom, 1989: pp. 6886): it is easy to get it wrong.

\section{Scenario 2: An extreme boundary violation}

$\operatorname{DrC}$ is approaching the end of his specialist training. He is allocated a young female patient, Ms D, who, in addition to considerable personality difficulties, has a fragile mood disorder and was referred after a major suicide attempt. During therapy Ms D's condition changes to a more sustained hypomanic episode during which she becomes overfamiliar, seductive and repeatedly asks Dr A out for dinner. She also 'makes' Dr A disclose that he is single and lives alone since a break-up with his last girlfriend. Dr A waits until Ms D's mental state stabilises and, after arranging the termination of therapy, accepts her dinner invitation. After few glasses of wine, they have consensual sex. They continue this relationship while Ms D is in therapy with another doctor.

Scenario 2 describes a case of sexual boundary violation which is perhaps atypical, in that the doctor is a trainee. However, it is entirely typical insofar as the patient is exceptionally vulnerable and in need not only of someone to depend on, but also of someone to rage against. Borderline personality disorder is more common in those who have a history of sexual exploitation; it is also associated with anger and mood dysregulation. It could be anticipated that the patient would idealise the therapist, and this idealisation would have a sexual component if she has a history of sexual abuse. The idealisation is a defence against denigration and rage, of which $\operatorname{Dr} C$ appears to have been completely unaware. Presumably because of his own needs, he took the idealisation at face value and used it to make himself feel better (and perhaps unconsciously to be revenged against his last partner).

This scenario also illustrates to some extent that sexual misconduct with a patient is usually a subtle and progressive phenomenon rather than a one-off sexual assault. Simon (1995) has called this the 'road much travelled' or the 'slippery slope' (Box 2).

\section{Existing professional and legal positions}

Serious boundary violations are unethical and, in some jurisdictions, are illegal. Most professional organisations consider sexual boundary violations to be unethical and state so explicitly in their code of ethics, or at least in their code of conduct (e.g.

Box 2 The 'slippery slope' or the 'road much travelled' (from Simon, 1995)

- Therapists' neutrality is eroded in 'little' ways

- Therapist and patient address each other by first names

- Therapy sessions become less clinical and more social

- Patient is treated as 'special' or confidant

- Therapist self-disclosures occur, usually about current personal problems and sexual fantasies about the patient

- Therapist begins touching patient, progressing to hugs and embraces

- Therapist gains control over patient, usually by manipulating the transference and by negligent prescribing of medication

- Extra-therapeutic contacts occur

- Therapy sessions are rescheduled for the end of the day

- Therapy sessions become extended in time

- Therapist stops billing the patient (in National Health Service settings this is not relevant)

- Therapist and patient have drinks/dinner after sessions; dating begins

- Therapist-patient sex begins 


\section{Box 3 Code of medical ethics of the American Medical Association (2001 revision: section 8.14)}

'Sexual contact that occurs concurrent with the physician-patient relationship constitutes sexual misconduct. Sexual or romantic interactions between physicians and patients distract from the goals of the physician-patient relationship, may exploit the vulnerability of the patient, may obscure the physician's objective judgment concerning the patient's healthcare, and ultimately may be detrimental to the patient's well-being. Sexual or romantic relationships between a physician and a former patient may be unduly influenced by the previous physician-patient relationship. Sexual or romantic relationship with former patients are unethical if the physician uses or exploits trust, knowledge, emotions or influence derived from the previous professional relationship.'

(c) American Medical Association. Reprinted with permission.

Boxes 3 and 4). Sexual activity with a patient is specifically proscribed only in the Hippocratic oath, which states:

'I will come for the benefit of the sick remaining free of all intentional injustice, of all mischief, and in particular of sexual relations with both female and male persons.'

Psychiatry was the first medical specialty to officially adopt such a stance on sexual boundary violations (Lazarus, 1995). The first edition of The Principles of Medical Ethics: With Annotations Especially Applicable to Psychiatry (American Psychiatric Association, 1972) stated simply, 'Sexual activity with a patient is unethical'. The text has undergone several revisions since, but the essentially unethical nature of this kind of relationship has always been highlighted.

Both the American Medical Association and the American Psychiatric Association have declared that sexual contact with a patient is unethical. The Canadian Psychiatric Association (1988) clearly states that 'eroticising the physician/patient relationship is unacceptable under any circumstances and cannot be rationalised as therapy'. In its annotations to the Canadian Medical Association's code of ethics it further states that:

'[the psychiatrist] must ensure that [therapy] does not lead to exploitation for personal gain, whether physical, emotional, religious, financial, sexual, or for any other reason ... The ethical psychiatrist will scrupulously maintain respect for the patient at all times and recognise and appropriately address transference and countertransference issues' (Canadian Psychiatric Association, 2002).

The scope of their guidance is thus broader than just sexual exploitation.

In the UK, ethical guidance on boundaries is provided by the GMC and should also be available from individual professional bodies. Among the duties of a doctor, the GMC merely lists the duty to 'avoid abusing your position as a doctor' (General Medical Council, 1994). However, the more recently revised GMC publication Good Medical Practice elaborates on this:

'In particular, you must not use your professional position to establish or pursue a sexual or improper emotional relationship with a patient or someone close to them' (General Medical Council, 2001).

The College has produced its own version of good medical practice, Good Psychiatric Practice (Royal College of Psychiatrists, 2000), which contains the same proscription of improper relationships. Vulnerable Patients, Vulnerable Doctors also describes good practice in clinical relationships and states clearly that 'relationships of sexual intimacy between doctor and patient are totally unacceptable' (Royal College of Psychiatrists, 2002: p. 23). Although no sanction is indicated, in the absence of a written code of ethics for British psychiatrists these are welcome documents.

\section{Box 4 Principles of medical ethics of the American Psychiatric Association (2001: section 2:1)}

'The requirement that the physician conduct himself/herself with propriety in his/her profession and in all the actions of his/her life is especially important in the case of the psychiatrist because the patient tends to model his/her behaviour after that of his/her psychiatrist by identification. Further, the necessary intensity of the treatment relationship may tend to activate sexual and other needs and fantasies on the part of both patient and psychiatrist, while weakening the objectivity necessary for control. Additionally, the inherent inequality in the doctor-patient relationship may lead to exploitation of the patient. Sexual activity with a current or former patient is unethical.'

(C) American Psychiatric Association. Reprinted with permission. 


\section{Sanctions and complaints}

Sanctions for improper behaviour include expulsion from the professional body, temporary or permanent deregistration and removal of licence to practice. This is justified under the broad rubric of bringing the profession into disrepute or conduct unbecoming of a professional. Lately, in the light of the more aggressive position adopted by the American Medical Association, physicians in the USA found guilty of sexual misconduct are facing harsher sanctions. Suspensions are longer and revocation is not infrequent. In the USA, such behaviour is also reported automatically to the National Practitioner's Data Bank (NPDB), a nationwide reference system (not open to the general public) that is referred to by all potential employers. In addition, even consensual sexual activity with a patient is a criminal offence in at least 18 states.

In the UK, sexual boundary violators may or may not be reported to the GMC, who will usually refer the case to its Professional Conduct Committee. Trusts may or may not have policies that deal with this issue directly; boundary violations of any sort undermine the integrity of care and are thus a matter for clinical governance policies. Doctors who regularly violate professional boundaries may also be dealt with under policies relating to poor performance, and complaints about such behaviour would be incorporated into the appraisal and revalidation process. In terms of the law, doctors involved in sexual relationships with their patients may (rarely) be charged with a criminal offence, but are more likely to be the subject of claims in negligence cases. Policies that outline the consequences vary from vague to non-existent. There are no consistent mandatory reporting requirements in the UK, and thus often it falls on the hapless patient to initiate proceedings. Of course, non-consensual sexual acts remain the domain of the criminal justice system, with its usual evidentiary requirements.

\section{Harm done by boundary violations}

Boundary violations harm patients by undermining the therapeutic process, and wrong them insofar as the doctor treats the patient merely as a means to an end. It is obvious that there is a power imbalance between doctor and patient, which can lead to exploitation. In sexual relationships, the harm comes because of the parallels with incest (Kardener, 1974) and the danger to the patient of making transferential fantasies real.

In terms of traditional medical ethics, doctors who abandon their professional identity for their own needs fail to respect the autonomy of their patients. The 'slippery slope' described by Simon gives the patients no real chance to choose their part in what occurs. For patients who have been similarly coerced by carers in the past, this is disastrous because every sexual act between a doctor and patient is, arguably, 'non-consensual'. There is a lack of intentionality, understanding and voluntariness, which means that the patient's autonomous authority is so restricted that apparent 'consent' is suspect. It is doubtful whether consent could be truly expressed in a relationship that is so evidently imbalanced in terms of power and dependence; assent is perhaps a better description.

It is well established that boundary violations, especially those of a sexual nature, do harm to the patient (Simon, 1995) and therefore undermine the doctor's ethical duty to benefit the patient, and not do them harm. The types of harm that may occur are listed in Box 5. In addition to direct harms such as relapse or worsening of symptoms there are indirect harms in terms of loss of trust and damage to selfesteem.

Sexual boundary violations usually result in abrupt termination of the therapy. The last contact with the professional is usually a negative experience and termination arrangements are rarely made. Only $20 \%$ of therapists in one study made a referral to another clinician (Disch \& Avery, 2001), and this failure to provide for ongoing care not only brings about the very abandonment that many patients in therapy fear, but also is a brutal indicator of how little therapists who have sex with their patients really care about them as people with psychological needs. Disch \& Avery also found that sexual relations with physicians are more damaging than with other types of professional, which indicate how much trust is lost by this type of behaviour.

Box 5 Some harmful consequences to the patient of boundary violations

- Emotional turmoil

- Shame, fear or rage

- Guilt and self-blame

- Isolation and emptiness, disengagement from services

- Cognitive distortion

- Identity confusion

- Emotional lability

- Sexual dysfunction

- Mistrust of authority, paranoia

- Depression

- Self-harm

- Suicide 
Adshead has suggested another harmful consequence: the loss of the therapist and their therapy (G. Adshead, personal communication, 2002). When the boundaries between patient and therapist break down, the patient often has no one to talk to about this, having lost the one person with whom they could discuss personal worries. In addition, the therapist may repeatedly impress on the patient the need to keep their illicit relationship secret because of the possible effects on the therapist's career. Thus, the patient is left with the responsibility of keeping something hidden to preserve the therapist's welfare. Such burden may be too much for the patient to bear, especially if the therapist is shamelessly coercive, in either a dependent or an aggressive manner.

Professionals are required to respect the principle of justice that patients be treated fairly. In light of the knowledge that sexual relationships with patients are inherently harmful, practitioners who engage in such activities can be seen as treating their patients unfairly. Moreover, health care decisions may be adversely influenced by the relationship, which would also be unjust.

\section{The slippery slope and the erosion of professional identity}

As mentioned above, Simon (1995) argued that a major boundary violation such as sexual misconduct does not occur out of the blue as a single event, but rather is the culmination of many small violations that the therapist allows to take place over time (Box 2) and that progressively erode professional identity.

How is it that the therapist allows the boundary violations to take place at all? It is clear from the literature that some patients are more at risk of being exploited in this way than others (Kluft, 1990), especially if they present with chaotic dependency needs. A key feature of many personality disorders is the inability to seek and obtain help effectively (Henderson, 1974), and flirtatious and seductive behaviours represent a type of faux-adult attempt to deny feelings of physical and psychological loneliness and to deal with the despair of perceiving themselves to be unwanted or not valued for themselves.

Idealisation can be hard to resist. In the face of personal problems, the therapist may look to a patient for narcissistic repair or love. However, a therapist's attraction to the patient is a toxic or malignant type of 'love', which does not have the other's welfare at heart. The therapist needs therefore to be prepared for this type of occupational hazard; to be constantly alert for seductiveness and neediness and the risk of boundary violations, in both their patients and themselves. This is not always easy or obvious. Many therapists believe that they intuitively know what boundaries are and how to maintain them. No level of training or school of therapy is immune from this. In fact, offenders are more likely to have been extensively trained, had personal therapy or analysis and to be senior in the profession.

There are many psychodynamic mechanisms that may be operating in therapists who abuse their professional position for personal gain, be it be emotional, sexual or financial (Box 6). Explanations range from the esoteric to the common (Gabbard, 1994). Among the common are stress and bereavement, whereas the more esoteric include unconscious re-enactment of incestuous longings and misinterpretation of the patient's desire for maternal nurturance as sexual overtures, which interlocks with the therapist's enactments of a rescue fantasy. Seeing the patient as the idealised version of one's 'self', confusion of the therapist's and the patient's needs, a fantasy that love is curative, and countertransference frustration (to ward off hatred and resentment) have all been blamed for violation of relationship boundaries. Some attribute it to the therapist's 'rebelliousness' or anger at the institution, to an attempt to break free from its archaic rules, and others call it 'manic defence' against mourning at termination.

Also among the esoteric explanations are 'exception fantasy' (when therapist believes that he is immune from action because of his 'special status') and 'masochistic surrender', perhaps aptly named because of the self-destructive effect that such acts can have on professional identity. Projective identification is thought to be a defence mechanism by which the physician allows a tormenting and sadistic patient, usually an incest victim, to demand more and more concrete proof of 'love'.

Box 6 Various mechanisms postulated in boundary violations

- Mismanaged transference

- Unconscious re-enactment of incestuous fantasy

- Rescue fantasy

- Countertransference frustration

- Rebellion against archaic institutional rules

- 'Manic defence' against mourning of termination

- Exception fantasy

- Masochistic surrender

- Projective identification

- 'Settling down the rowdy man' 
Some mechanisms may be specific to, or at least more common in, female therapists. One such is the belief that they are 'settling down the rowdy man'. Female therapists may also be more likely to have childhood histories of abuse and exploitation, which can be enacted in unconsciously aggressive ways in their relationship with patients.

Gabbard (1994) and Schoener (1995) have proposed classification systems for abusive doctors. These include categories based on many of the mechanisms mentioned above and also categories of mental illness such as bipolar disorder and psychosis. It is likely that a small subgroup of abusive doctors are sociopathic in other ways, and these individuals may act in predatory ways towards patients. It is also possible that some abusive doctors were themselves subjected to boundary-violating behaviour as students or as patients in therapy (Pope et al, 1979; Goodwin, cited in Lazarus, 1995).

Gabbard \& Peltz (2001) describe a particularly malignant variety of abusive experience, in which the violations occurred in the context of the training analyst-candidate dyad. They argue that such institutional abuse has huge long-term potential for future harm, what they call 'poisoning the well' of future generations of therapists. The mechanism of harm in these special situations is essentially the same as in doctor-patient boundary violations, but it assumes special importance when the longterm implications are considered.

The danger in finding an acceptable mechanism that explains violations is that post hoc rationalisation comes into play. The human-ness of the players, proximity, sharing an intimate space, opportunity - all have been traditionally blamed by sexual offenders as much as by abusive therapists. At one time, it was acceptable to terminate therapy to marry one's patient, and the notion of 'toxic love' is still invoked in some circles. None of these excuses takes into consideration that, in addition to the inherent power discrepancy, there is the phenomenon of transference operating in the relationship. While transference remains the cornerstone of any successful therapeutic relationship (particularly in psychoanalysis), it is the mismanagement of transference and countertransference that causes most boundary violations. Perhaps this is why psychoanalysis as a profession was (and still is) notorious for well-publicised cases of sexual violations by senior analysts. Psychotherapists as professionals (perhaps rivalled only by the clergy) remain at the forefront of violations of a serious type. In the end, it appears that boundary violations take place when therapists choose action over reflection.

\section{Prevention and education}

In an ideal world, these power-discrepant relationships would not be tolerated. In reality, the abuse continues and the spectrum of abusers and forms of abuse continue to grow. There is some evidence (Lazarus, 1995), at least in the USA, that the incidence of sexual abuse by psychiatrists (measured by the number of reported cases per 1000 members) is falling. Whether this is due to the deterrent effect of the increasing refusal of professional liability carriers to insure against boundary violations or the ever-increasing amount of damages awarded is not known. One would hope that education and training to foster awareness in this area has had an impact. Research conducted in a medical school/ residency programme in Australia (Vamos, 2001) showed that, with very little intervention, awareness could be greatly increased - and increased awareness can go a long way to protect against future violations. The numbers in the study were perhaps too low to give such a claim any great validity, but the principles behind such intervention can easily be understood.

Any educational programme should at least take into consideration the universality of the phenomenon and recognise how easily boundaries can be crossed. Erotic feelings towards one's patients are a normal emotional reaction: for example, Garrett (2002) records that as much as $85 \%$ of a sample of Dutch male gynaecologists and $80-85 \%$ of a group of American psychologists reported such feelings. How to use those emotions to understand the patient is perhaps a fine art that has to be learned painstakingly. The difference between 'liking' and 'love' is also an important distinction that has to be learned, if necessary through personal therapy. It is important to recognise those feelings early, if a properly managed termination is to be achieved. Merely learning about boundaries often is not enough. Ethics cannot be taught in a vacuum and the principles of transference and countertransference should be part of any curriculum, irrespective of whether the trainees go on to practise psychotherapy or not. Mishandling transference is arguably the most frequent cause of boundary violations and training in this area may ultimately be the most useful intervention.

Supervision, it often has been said, provides the best safeguard against bad practice. Apart from being a clinical requirement, it is salutary to be supervised if any form of psychotherapy is practised. One can never be too old or too senior for supervision, and examining the history of offenders in this area often reveals that they worked alone, without a supervisor. When in doubt, a professional should be consulted, not a 'friend'. 
This especially is true for therapists who are going through personal difficulties, whether or not the source of the difficulty is in a personal relationship.

Intervention at the personal level has twofold benefit: it will increase awareness and, as a byproduct, gradually reduce the number of incidents. At the institutional level, intervention will produce more thoughtful and ethical clinicians. The overall cost of a publicised case of sexual abuse by a professional attached to an institution is inestimable, even if the legal cost can be covered. Institutions may also be legally required to carry large liability coverage for the clinicians that are employed by it. Merely having policies or guidelines, if they are not enforced or closely scrutinised for compliance, will not be enough if determination of liability becomes a matter for the courts.

\section{Conclusions}

A famous American psychoanalyst of her time, Frieda Fromm-Reichman, perhaps was being facetious when she reportedly said, 'Don't have sex with your patients; you will only disappoint them'. She also grossly understated the problem. The cost of sexual contact with a patient is immense, for the profession and for the two involved parties. Therapist-patient sexual contact is always unethical; it is also inherently harmful. There may be argument as to whether any form of boundary violation is inherently harmful and thus unethical. Not all minor violations progress to full-fledged sexual activity, but all sexual activity probably started with some 'minor' violation. Gorovitz (1982: pp. 167-168) suggests that good 'skiers' can negotiate ethical 'slippery slopes'; but perhaps this is one slope we should avoid, irrespective of our skiing skills. The discussion in the literature convincingly shows that no good comes from any of these transgressions and that both parties can suffer much harm. Although erotic feelings on both sides are common in caring relationships, only about $10 \%$ of therapists act on them (Garrett, 2002). The responsibility to examine our feelings and thoughts is ours only, and in us lies the power to stop the progression of a thought or feeling into action. Education, awareness and, importantly, supervision may all help, but they cannot stop us if we are not self-reflective. The patient should never be used to contain our unpleasant affects, nor should he or she be expected to carry this heavy burden. In the end, the following warning, albeit prescriptive, remains a salutary reminder:

'It is ALWAYS [the therapist's] responsibility to know what is appropriate and never to cross the line into sexual activity' (College of Physicians and Surgeons of Ontario, 1991).

\section{References}

American Medical Association (2002) Code of Medical Ethics: Current Opinions with Annotations (2002-2003 edn). Chicago, IL: AMA.

American Psychiatric Association (1972) The Principles of Medical Ethics. With Annotations Especially Applicable to Psychiatry. Washington, DC: APA.

American Psychiatric Association (2001) The Principles of Medical Ethics. With Annotations Especially Applicable to Psychiatry. Washington, DC: APA. http://www.psych. org/public_info/patient_\&_fam.cfm

Borys, D. S. \& Pope, K. S. (1989) Dual relationship between therapist and the client: a national study of psychologists, psychiatrists and social workers. Professional Psychology: Research and Practice, 20, 283293.

Canadian Psychiatric Association (1988) Sexual Exploitation of Patients: The Position of the Canadian Psychiatric Association. http://www.cpa-apc.org/Publications / Position_Papers/Sexual.asp

Canadian Psychiatric Association (2002) The 1996 CMA Code of Ethics Annotated for Psychiatrists. http://www.cpa-apc.org/ Publications/Position_Papers/annotatedCodeOfEthics/ codeOfEthics.html

College of Physicians and Surgeons of Ontario (1991) The Final Report of the Task Force on Sexual Abuse of Patients. Toronto: College of Physicians and Surgeons of Ontario.

Disch, E. \& Avery, N. (2001) Sex in the consulting room, the examining room, and the sacristy: survivors of sexual abuse by professionals. American Journal of Orthopsychiatry, 71, 204-217.

Gabbard, G. O. (1994) Psychotherapists who transgress sexual boundaries with patients. Bulletin of the Menninger Clinic, 58, 124-135.

Gabbard, G. O. \& Peltz, M. L. (2001) Speaking the unspeakable: institutional reactions to boundary violations by training analysts. Journal of the American Psychoanalytic Association, 49, 659-673.

Garrett, T. (2002) Inappropriate therapist-patient relationships. In Inappropriate Relationships (eds R. Goodwin \& D. Cramer), pp. 147-170. Mahwah, NJ: Lawrence Erlbaum.

Garrett, T. \& Davis, J. (1998) The prevalence of sexual contact between British clinical psychologists and their patients. Clinical Psychology and Psychotherapy, 5, 253256.

Gartrell, N., Herman, J., Olarte, S., et al (1986) Psychiatristpatient sexual contact: results of a national survey. I: Prevalence. American Journal of Psychiatry, 143, 11261131.

General Medical Council (1994) Duties of a Doctor. London: GMC

General Medical Council (2001) Good Medical Practice. London: GMC.

Gorovitz, S. (1982) Doctors' Dilemmas: Moral Conflict and Medical Care. Oxford \& New York: Oxford University Press.

Gutheil, T. G. \& Gabbard, G. O. (1993) The concept of boundaries in clinical practice: theoretical and riskmanagement dimensions. American Journal of Psychiatry, 150, 188-196.

Henderson, S. (1974) Care-eliciting behaviour in man. Journal of Nervous Disease, 159, 172-181.

Kardener, S. H. (1974) Sex and the physician-patient relationship. American Journal of Psychiatry, 131, 11341136.

Kluft, R. P. (1990) Incest and subsequent re-victimization: the case of therapist-patient sexual exploitation with a description of 'sitting-duck' syndrome. In Incest-Related Syndromes of Adult Psychopathology (ed. R. P. Kluft). Washington, DC: American Psychiatric Press.

Lazarus, J. A. (1995) Ethical issues in doctor-patient sexual relationships. Psychiatric Clinics of North America, $18,55-70$ 
Perr, I. N. (1989) Medico-legal aspects of professional sexual exploitation. In Sexual Exploitation in Professional Relationships (ed. G. O. Gabbard), pp. 211-228. Washington, DC: American Psychiatric Press.

Pope, K. S., Levenson, H. \& Schover, L. R. (1979) Sexual intimacy in psychology training: results and implications on a national survey. American Psychologist, 34, 682689.

Pope, K. S. (1991) Rehabilitation plans and expert testimony for therapists who have been sexually involved with a patient. Independent Practitioner, 22 (3), 31-39.

Quadrio, C. (1996) Sexual abuse in therapy: gender issues Australian and New Zealand Journal of Psychiatry, 30, 125133.

Royal College of Psychiatrists (2000) Good Psychiatric Practice 2000 (Council Report CR83). London: Royal College of Psychiatrists.

Royal College of Psychiatrists (2002) Vulnerable Patients, Vulnerable Doctors: Good Practice in Our Clinical Relationships (Council Report CR101). London: Royal College of Psychiatrists.

Schoener, G. R. (1995) Assessment of professionals who have engaged in boundary violations. Psychiatric Annals, 25 95-99.

Simon, R. I. (1995) The natural history of therapist sexual misconduct: identification and prevention. Psychiatric Annals, 25, 90-94.

Vamos, M. (2001) The concept of appropriate professional boundaries in psychiatric practice: a pilot training course Australian and New Zealand Journal of Psychiatry, 35, 613618.

Yalom, I. (1989) Love's Executioner and Other Tales of Psychotherapy. London: Bloomsbury.

\section{Multiple choice questions}

1 As regards professional boundary violations:

a they are a binary phenomenon

b they are a uniquely North American problem

c physicians are most often the offenders

d no discipline or school of psychiatry is immune

e all such violations are illegal.
2 Research on therapist-patient sexual contact shows that:

a a particular type of patient is more vulnerable

$b$ there is a particular profile of the offending professional

c classification of offenders is helpful in understanding the dynamics

d harm caused is negligible and easily repaired

e patients are often motivated by revenge.

3 Harm caused by professional boundary violations:

a can be severe

$\mathrm{b}$ includes improper and badly managed termination of therapy

c is due to mismanaged transference

$\mathrm{d}$ is restricted to the patient

e is not related to the professional background of the abuser.

4 The following mechanisms may be operating in the therapist in an inappropriate relationship:

a rebelliousness against archaic professional rules

b confusion over the therapist's needs $v$. the patient's needs

c countertransference frustration

d rescue fantasy

e genuine love for the patient.

5 The literature on boundary violation shows that:

a offenders are not like 'us'

b explanations for this behaviour occupy a wide range, from the common to the esoteric

c female therapists are immune from offending

d repeated boundary crossing may lead to major violations

e education on boundaries and transference issues may guard against future violations in trainees. 